\title{
Hospitalization costs among immobile patients with hemorrhagic or ischemic stroke in China: a multicenter cross- sectional study
}

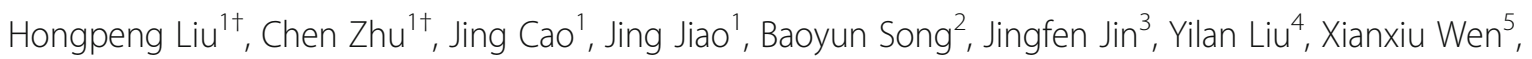
Shouzhen Cheng ${ }^{6}$ and Xinjuan $\mathrm{Wu}^{1 *}$

\begin{abstract}
Background: In this study, we aimed to analyze the hospitalization costs for immobile patients with hemorrhagic stroke (IHS) or ischemic stroke (IIS) in China and to determine the factors associated with hospitalization costs.

Methods: We evaluated patients with IHS and IIS hospitalized between November 2015 and July 2016 in six provinces or municipality cities of China. Linear regression analysis was used to examine the association with hospitalization costs and predictors.

Results: In total, 1573 patients with IHS and 3143 with IIS were enrolled and analyzed. For IHS and IIS, the average length of stay (LOS) was $17.40 \pm 12.3$ and $14.47 \pm 11.55$ days. The duration of immobility was $12.11 \pm 9.98$ and $7.36 \pm$ 9.77 days, respectively. Median hospitalization costs were RMB 47000.68 (interquartile range 19,827.37, 91,877.09) for IHS and RMB 16578.44 (IQR 7020.13, 36,357.65) for IIS. In both IHS and IIS groups, medicine fees accounted for more than one-third of hospitalization costs. Materials fees and medical service fees accounted for the second and third largest proportions of hospital charges in both groups. Linear regression analysis showed that LoS, hospital level, and previous surgery were key determinants of hospitalization costs in all immobile patients with stroke. Subgroup analysis indicated that hospital level was highly correlated with hospitalization costs for IHS whereas pneumonia and deep vein thrombosis were key factors associated with hospitalization costs for IIS.

Conclusions: We found that hospitalization costs were notably higher in IHS than IIS, and medicine fees accounted for the largest proportion of hospitalization costs in both patient groups, perhaps because most patients ended up with complications such as pneumonia thereby requiring more medications. LoS and hospital level may greatly affect hospitalization costs. Increasing the reimbursement ratio of medical insurance for patients with IHS is recommended. Decreasing medicine fees and LoS, preventing complications, and improving treatment capability may help to reduce the economic burden of stroke in China.
\end{abstract}

Keywords: Hospitalization costs, Stroke subtype, Prospective observational study, Multicenter, China

\footnotetext{
* Correspondence: wuxinjuan@sina.com

${ }^{\dagger}$ Hongpeng Liu and Chen Zhu contributed equally to this work.

'Department of Nursing, Chinese Academy of Medical Sciences - Peking

Union Medical College, Peking Union Medical College Hospital, 1

Shuaifuyuan, Dongcheng District, Beijing 100730, China

Full list of author information is available at the end of the article
}

\section{$\triangle B M C$}

(c) The Author(s). 2020 Open Access This article is licensed under a Creative Commons Attribution 4.0 International License, which permits use, sharing, adaptation, distribution and reproduction in any medium or format, as long as you give appropriate credit to the original author(s) and the source, provide a link to the Creative Commons licence, and indicate if changes were made. The images or other third party material in this article are included in the article's Creative Commons licence, unless indicated otherwise in a credit line to the material. If material is not included in the article's Creative Commons licence and your intended use is not permitted by statutory regulation or exceeds the permitted use, you will need to obtain permission directly from the copyright holder. To view a copy of this licence, visit http://creativecommons.org/licenses/by/4.0/ The Creative Commons Public Domain Dedication waiver (http://creativecommons.org/publicdomain/zero/1.0/) applies to the data made available in this article, unless otherwise stated in a credit line to the data. 


\section{Background}

Stroke is a main cause of morbidity and mortality in low- and middle-income countries $[1,2]$. China accounts for approximately one in three of the total deaths owing to stroke globally [3]. Estimates in 2013 were of nearly 2.4 million new strokes and 1.1 million stroke-related deaths, with 11.1 million stroke survivors alive at any given time $[3,4]$. Stroke is also a serious disease in economic terms in China [5, 6]. The annual cost for stroke treatment was estimated to be RMB 37.5 billion in 2015, with the total cost rising to approximately RMB 50 billion if indirect costs are included [7].

With the lifestyle changes taking place in China together with economic growth, as well as an ongoing high prevalence, the number of patients with stroke and its hospitalization costs are rising $[8,9]$. Although many medical care resources have been invested in stroke management [4], the costs for the main stroke subtypes vary owing to different potentially associated factors. Understanding the cost composition and the differences in stroke subtypes can help policymakers discern which types of cost and which contributors are driving increases in spending [10].

Previous studies have reported the economic burden of stroke treatment and care, but the results were limited to only one subtype of stroke [11, 12]. Retrospective observational studies have also been conducted, based on the Beijing Public Health Information Center database; however, this database only includes cost data from one region and therefore lacks representativeness [10-12]. Another study used cost data based on a single-center database, with a comparatively limited sample size [7]. In addition, previous reports have not focused on the hospitalization costs for immobile patients with stroke, who are often chronically impaired in their movement, often resulting in other comorbidities or medical complications that increase the economic burden to a certain extent $[13,14]$.

The present study was derived from a research project of the National Health and Family Planning Commission of the People's Republic of China, which aimed to develop a standardized nursing intervention model (SNIM) among immobile patients with stroke. As part of baseline investigations for this large-scale prospective study, we carried out the present study, to provide a descriptive summary of factors associated with hospitalization cost estimates for immobile patients with hemorrhagic stroke (IHS) or ischemic stroke (IIS) in six different geographic regions of China. Furthermore, we explored differences in the contributors to ischemic and hemorrhagic stroke.

\section{Methods}

\section{Study population}

Study participants were enrolled in the SNIM study, which was conducted in 25 public general hospitals covering six provinces or municipality cities of China (Beijing municipality city and Henan, Zhejiang, Guangdong, Hubei, and Sichuan provinces) from November 2015 to July 2016 (Fig. 1). Figure 1. was designed by the research team and edited by the PowerPoint 2013, it was not taken from another source. Further information about the SNIM study has been published elsewhere [15]. Patients with stroke comprised 4716 patients with principal diagnosis codes I60.x, I61.x, H34.1, I63.x, I64.x, according to the International Classification of Diseases, Tenth Revision. Patients were categorized according to hemorrhagic (I60.x, I61.x) and ischemic (H34.1, I63.x, I64.x) stroke $[2,16]$. Immobility was defined as when the patient's

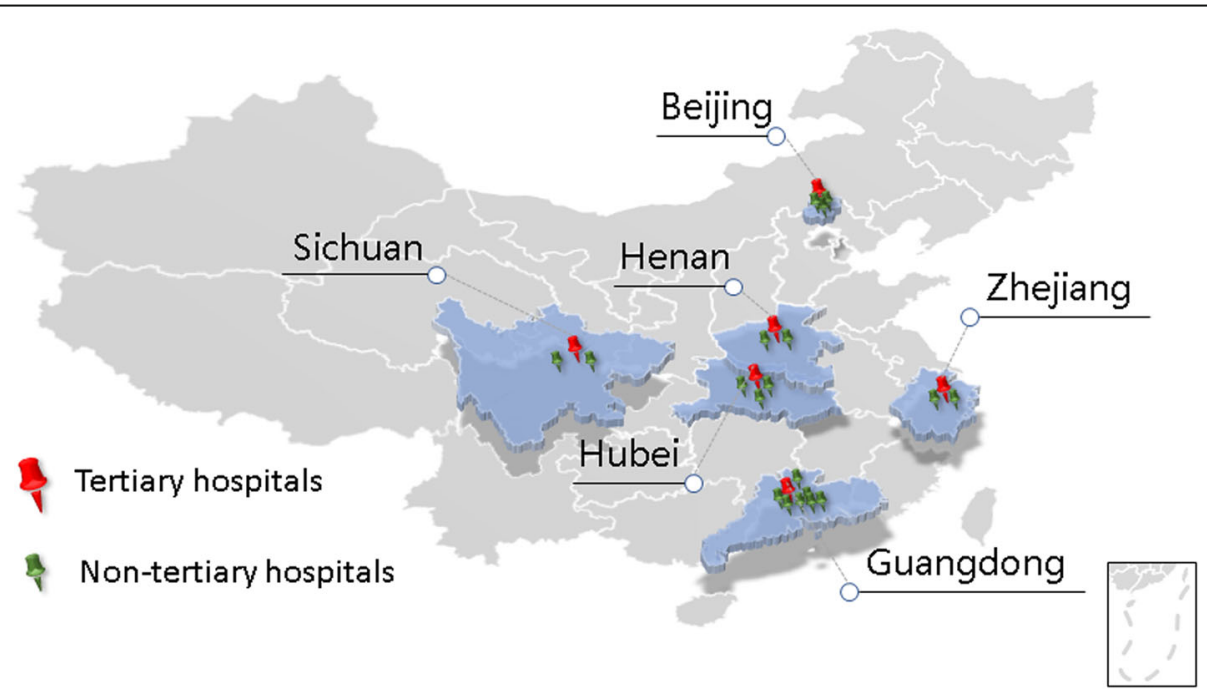

Fig. 1 Location of hospitals included in this study. It was designed by the research team and edited by PowerPoint 2013. It was not taken from another source 
basic physiological needs were carried out in bed, except for active or passive bedside sitting/standing/ wheelchair use for examination.

This study was ethically approved by the authorities of the 25 cooperating hospitals in six provinces or municipality cities of China, and participants signed a written informed consent before enrolment. All patient records and information were anonymized and deidentified prior to the analysis.

\section{Definition of covariates}

Potential factors associated with hospitalization costs in the models included sociodemographic characteristics and clinical characteristics. Sociodemographic characteristics comprised age, sex, hospital level, and payment type. Clinical characteristics consisted of the patient's body mass index (BMI); previous ICU admission; previous surgery; hospital length of stay (LoS); duration of immobility; major immobility complications (MICs) including pressure injury (PI), deep vein thrombosis (DVT), pneumonia, and urinary tract infection (UTI); invasive ventilation therapy; respiratory invasive operation; tracheotomy, urethral invasive operation; disorders of consciousness; immobility status at discharge; and Charlson Comorbidity Index (CCI) score. CCI was categorized according to scores of $0-3,4,5$, and 6 or above. Total hospitalization costs consisted of costs for medicine, materials, medical services, laboratory and examination fees, nursing, blood transfusion, and other costs.

\section{Statistical analysis}

Descriptive statistical methods were used for demographic characteristics. Continuous variables were described as mean \pm standard deviation (SD) or median (interquartile range, IQR), and categorical variables were represented as number (percentage). In univariate analysis, we used the Wilcoxon signed-rank test and Kruskal-Wallis test to assess the associated factors. Then, associations of sociodemographic or clinical characteristics with hospitalization costs were analyzed using a multiple linear regression model. All parameters with a $P<0.05$ in univariate analysis were included in the multivariate analyses. For categorical variables such as payment type, we used the "Enter" method, after transferring these to the dummy variables. Levels of significance $P<0.05$ for inclusion and $P>0.10$ for exclusion were used for the other parameters in the stepwise procedure. We used three multiple linear regression models for all immobile patients with stroke, immobile patients with hemorrhagic stroke (IHS), and immobile patients with ischemic stroke (IIS), respectively. A two-sided $P$ value $<0.05$ was considered to indicate statistical significance. IBM SPSS version 19 for Windows (IBM Corp, Armonk, NY, USA) was used for all statistical analyses.

\section{Results}

\section{Demographics}

We included a total 4716 immobile patients with stroke requiring hospitalization between November 2015 and July 2016 (Table 1 ). Mean patient age was $63.39 \pm 14.48$ years. Among the total, 1573 (33.35\%) had hemorrhagic stroke, 3143 (66.64\%) had ischemic stroke; 2726 (57.8\%) were men and 1990 (42.2\%) were women. In total, 36.7 and $35.3 \%$ of IHS had previous ICU admission and previous surgery, respectively; these rates were 12.7 and $12.1 \%$, respectively, in IIS. The average LoS and duration of immobility was $15.45 \pm 11.89$ days and $8.94 \pm 10.09$ days, respectively, for all patients. IHS had longer LoS (17.40 \pm 12.31 days vs. $14.47 \pm 11.55$ days $)$ and duration of immobility ( $12.11 \pm 9.98$ days vs. $7.36 \pm 9.77$ days) than IIS. Medical insurance covered approximately $73 \%$ patients; $42.9 \%$ of patients were supported by the new cooperative medical system (NCMS) insurance whereas $20.0 \%$ were self-paying. A total $3158(67.0 \%)$ patients were in tertiary hospitals and $1558(33.0 \%)$ were in nontertiary hospitals. The most common MIC among immobile patients with stroke was pneumonia. IHS received more medical treatment or nursing interventions than those with ischemic stroke, such as invasive ventilation therapy and respiratory or urethral invasive operations.

\section{Hospitalization costs among immobile patients with stroke} Figure 2 depicts hospitalization costs, according to category. The average hospitalization costs for all immobile patients with stroke was RMB 42,319.67 $\pm 53,986.27$ and median hospitalization costs were RMB 22,656.79 (IQR RMB 9016.51, 56,486.00). Fees for medicine, materials, medical services, and laboratory and examination fees constituted $37.42,24.70,21.94$, and $13.38 \%$ of the hospitalization costs in all immobile patients with stroke. Fees for nursing $(1.83 \%)$, blood transfusion $(0.29 \%)$, and other fees $(0.45 \%)$ accounted for the minimum proportion in the distribution (Fig. 2a). In the subgroup analysis, the cost category distributions were consistent for the distribution of costs in IHS and IIS (Fig. $2 \mathrm{~b}$ and c). In comparison with IIS, IHS had higher materials fees (26.81\% vs. $22.42 \%)$, medical service fees $(25.04 \%$ vs. $18.58 \%)$, and nursing fees ( $1.89 \%$ vs. $1.76 \%)$.

\section{Potential factors associated with hospitalization costs}

Supplementary Table 1 demonstrates the results of univariate analysis for the factors associated with hospitalization costs in all immobile patients with stroke. The findings suggest that stroke subtype, age, CCI score, previous ICU admission, previous surgery, payment type, hospital level, MICs, invasive ventilation therapy, respiratory invasive operation, tracheotomy, urethral invasive operation, disorders of consciousness, and immobility status at discharge were all associated with hospitalization costs. 
Table 1 Characteristics of immobile patients with stroke

\begin{tabular}{|c|c|c|c|}
\hline & $\begin{array}{l}\text { Total } \\
(n=4716)\end{array}$ & $\begin{array}{l}\text { Hemorrhagic } \\
(n=1573)\end{array}$ & $\begin{array}{l}\text { Ischemic } \\
(n=3143)\end{array}$ \\
\hline \multicolumn{4}{|l|}{ Age group, n (\%) } \\
\hline 18-44 years old & $440(9.3 \%)$ & $256(16.3 \%)$ & 184(5.9\%) \\
\hline 45-64 years old & 1949(41.3\%) & $874(55.6 \%)$ & 1075(34.2\%) \\
\hline 65 years old and above & 2327(49.3\%) & $443(28.2 \%)$ & 1884(59.9\%) \\
\hline \multicolumn{4}{|l|}{ Sex, n (\%) } \\
\hline Male & $2726(57.8 \%)$ & $896(57.0 \%)$ & $1830(58.2 \%)$ \\
\hline Female & 1990(42.2\%) & $677(43.0 \%)$ & $1313(41.8 \%)$ \\
\hline BMI & $23.82 \pm 3.34$ & $23.89 \pm 3.43$ & $23.78 \pm 3.30$ \\
\hline \multicolumn{4}{|l|}{ Previous ICU admission, n (\%) } \\
\hline Yes & $976(20.7 \%)$ & $578(36.7 \%)$ & $398(12.7 \%)$ \\
\hline No & $3740(79.3 \%)$ & $995(63.3 \%)$ & $2745(87.3 \%)$ \\
\hline \multicolumn{4}{|l|}{ Previous surgery, n (\%) } \\
\hline Yes & $936(19.8 \%)$ & $556(35.3 \%)$ & $380(12.1 \%)$ \\
\hline No & $3780(80.2 \%)$ & $1017(64.7 \%)$ & $2763(87.9 \%)$ \\
\hline LOS & $15.45 \pm 11.89$ & $17.40 \pm 12.31$ & $14.47 \pm 11.55$ \\
\hline Duration of immobility, n (\%) & $8.94 \pm 10.09$ & $12.11 \pm 9.98$ & $7.36 \pm 9.77$ \\
\hline \multicolumn{4}{|l|}{ Number of CCl, n (\%) } \\
\hline $0-3$ & $1471(31.2 \%)$ & $861(54.7 \%)$ & $610(19.4 \%)$ \\
\hline 4 & $973(20.6 \%)$ & $389(24.7 \%)$ & $584(18.6 \%)$ \\
\hline 5 & $1151(24.4 \%)$ & $230(14.6 \%)$ & $921(29.3 \%)$ \\
\hline 6 and above & $1121(23.8 \%)$ & $93(5.9 \%)$ & 1028(32.7\%) \\
\hline \multicolumn{4}{|l|}{ Payment type, n (\%) } \\
\hline UEBMI & $659(14.0 \%)$ & $182(11.6 \%)$ & $477(15.2 \%)$ \\
\hline URBMI & $759(16.1 \%)$ & $179(11.4 \%)$ & $580(18.5 \%)$ \\
\hline NCMS & 2023(42.9\%) & $636(40.4 \%)$ & 1387(44.1\%) \\
\hline The Public Health Insurance Program & $114(2.4 \%)$ & $28(1.8 \%)$ & $86(2.7 \%)$ \\
\hline Self-paying & $945(20.0 \%)$ & $464(29.5 \%)$ & $481(15.3 \%)$ \\
\hline Others & $216(4.6 \%)$ & $84(5.3 \%)$ & $132(4.2 \%)$ \\
\hline \multicolumn{4}{|l|}{ Hospital level, n (\%) } \\
\hline Tertiary hospital & $3158(67.0 \%)$ & 1324(84.2\%) & $1834(58.4 \%)$ \\
\hline Non-tertiary hospital & 1558(33.0\%) & $249(15.8 \%)$ & $1309(41.6 \%)$ \\
\hline \multicolumn{4}{|l|}{ PI, n (\%) } \\
\hline Yes & $60(1.3 \%)$ & $26(1.7 \%)$ & $34(1.1 \%)$ \\
\hline No & $4656(98.7 \%)$ & 1547(98.3\%) & 3109(98.9\%) \\
\hline \multicolumn{4}{|l|}{ DVT, n (\%) } \\
\hline Yes & $50(1.1 \%)$ & $24(1.5 \%)$ & $26(0.8 \%)$ \\
\hline No & $4666(98.9 \%)$ & 1549(98.5\%) & $3117(99.2 \%)$ \\
\hline \multicolumn{4}{|l|}{ Pneumonia, n (\%) } \\
\hline Yes & $475(10.1 \%)$ & $230(14.6 \%)$ & $245(7.8 \%)$ \\
\hline No & $4241(89.9 \%)$ & $1343(85.4 \%)$ & $2898(92.2 \%)$ \\
\hline \multicolumn{4}{|l|}{ UTI, n (\%) } \\
\hline Yes & $64(1.4 \%)$ & $36(2.3 \%)$ & $28(0.9 \%)$ \\
\hline No & 4652(98.6\%) & 1537(97.7\%) & 3115(99.1\%) \\
\hline
\end{tabular}


Table 1 Characteristics of immobile patients with stroke (Continued)

\begin{tabular}{|c|c|c|c|}
\hline & $\begin{array}{l}\text { Total } \\
(n=4716)\end{array}$ & $\begin{array}{l}\text { Hemorrhagic } \\
(n=1573)\end{array}$ & $\begin{array}{l}\text { Ischemic } \\
(n=3143)\end{array}$ \\
\hline \multicolumn{4}{|c|}{ Invasive ventilation therapy, n (\%) } \\
\hline Yes & $508(10.8 \%)$ & $324(20.6 \%)$ & $184(5.9 \%)$ \\
\hline No & $4208(89.2 \%)$ & $1249(79.4 \%)$ & 2959(94.1\%) \\
\hline \multicolumn{4}{|c|}{ Respiratory invasive operation } \\
\hline Yes & $60(1.3 \%)$ & $40(2.5 \%)$ & $20(0.6 \%)$ \\
\hline No & $4656(98.7 \%)$ & 1533(97.5\%) & $3123(99.4 \%)$ \\
\hline \multicolumn{4}{|c|}{ Tracheotomy } \\
\hline Yes & $641(13.6 \%)$ & $413(26.3 \%)$ & $228(7.3 \%)$ \\
\hline No & $4075(86.4 \%)$ & $1160(73.7 \%)$ & 2915(92.7\%) \\
\hline \multicolumn{4}{|c|}{ Urethral invasive operation } \\
\hline Yes & $1318(27.9 \%)$ & $779(49.5 \%)$ & $539(17.1 \%)$ \\
\hline No & $3398(72.1 \%)$ & $794(50.5 \%)$ & $2604(82.9 \%)$ \\
\hline \multicolumn{4}{|c|}{ Disorder of consciousness, n (\%) } \\
\hline Yes & $791(16.8 \%)$ & $506(32.2 \%)$ & 285(9.1\%) \\
\hline No & 3925(83.2\%) & 1067(67.8\%) & 2858(90.9\%) \\
\hline \multicolumn{4}{|c|}{ Immobility status at discharge, $\mathrm{n}(\%)$} \\
\hline Yes & $1641(34.8 \%)$ & $727(46.2 \%)$ & $914(29.1 \%)$ \\
\hline No & $3075(65.2 \%)$ & $846(53.8 \%)$ & $2229(70.9 \%)$ \\
\hline
\end{tabular}

Multivariate analysis was then carried out using those factors that were significant in the univariate analysis. Table 2 and Supplementary Table 4 show the results of multivariate analysis for hospitalization costs in immobile patients with stroke. In the stepwise regression model, LoS, hospital level, and previous surgery were found to be significant determinants of hospitalization costs $(P<0.001)$. The factors influencing coefficients of association, from highest to lowest, were LoS, hospital level, previous surgery, previous ICU admission, invasive ventilation therapy, urethral invasive operation, respiratory invasive operation, pneumonia, and stroke subtype (adjusted $\mathrm{R}^{2}=0.512, P<0.001$ ).

\section{Subgroup analysis of the factors associated with hospitalization costs}

The results of univariate analysis for factors associated with hospitalization costs in IHS and IIS are shown in Supplementary Tables 2 and 3. Multivariate analysis was performed using the factors that were significant in the univariate analysis. The statistically significant predictors of hospitalization costs of IHS and IIS in the stepwise multiple linear regression model are shown in Tables 3 and 4 and Supplementary Table 4. According to standardized coefficients, the associated factors in IHS, in decreasing order, were hospital level, LoS, previous surgery, duration of immobility, previous ICU admission, respiratory invasive operation, urethral invasive operation, and invasive ventilation therapy (adjusted $R^{2}=0.421, P<0.001$ ). In IIS (see Table 4), the factors associated with hospitalization costs, in decreasing order, were LoS, hospital level, previous ICU admission, previous surgery, invasive ventilation therapy, urethral invasive operation, respiratory invasive operation, pneumonia, and DVT (adjusted $\mathrm{R}^{2}=0.536, P<0.001$ ).

\section{Discussion}

In China, the stroke burden is expected to increase further as a result of population aging and an ongoing high prevalence of risk factors for stroke; however, the costs for different stroke subtypes have not been comprehensively analyzed. Describing the distribution and characteristics of the hospitalization costs in stroke and examining the associated factors are essential steps to providing high-quality health care services while avoiding increasing the socioeconomic burden. To the best of our knowledge, our study is the latest study that analyzes the distribution and potential factors associated with hospitalization costs for different subtypes of stroke in 


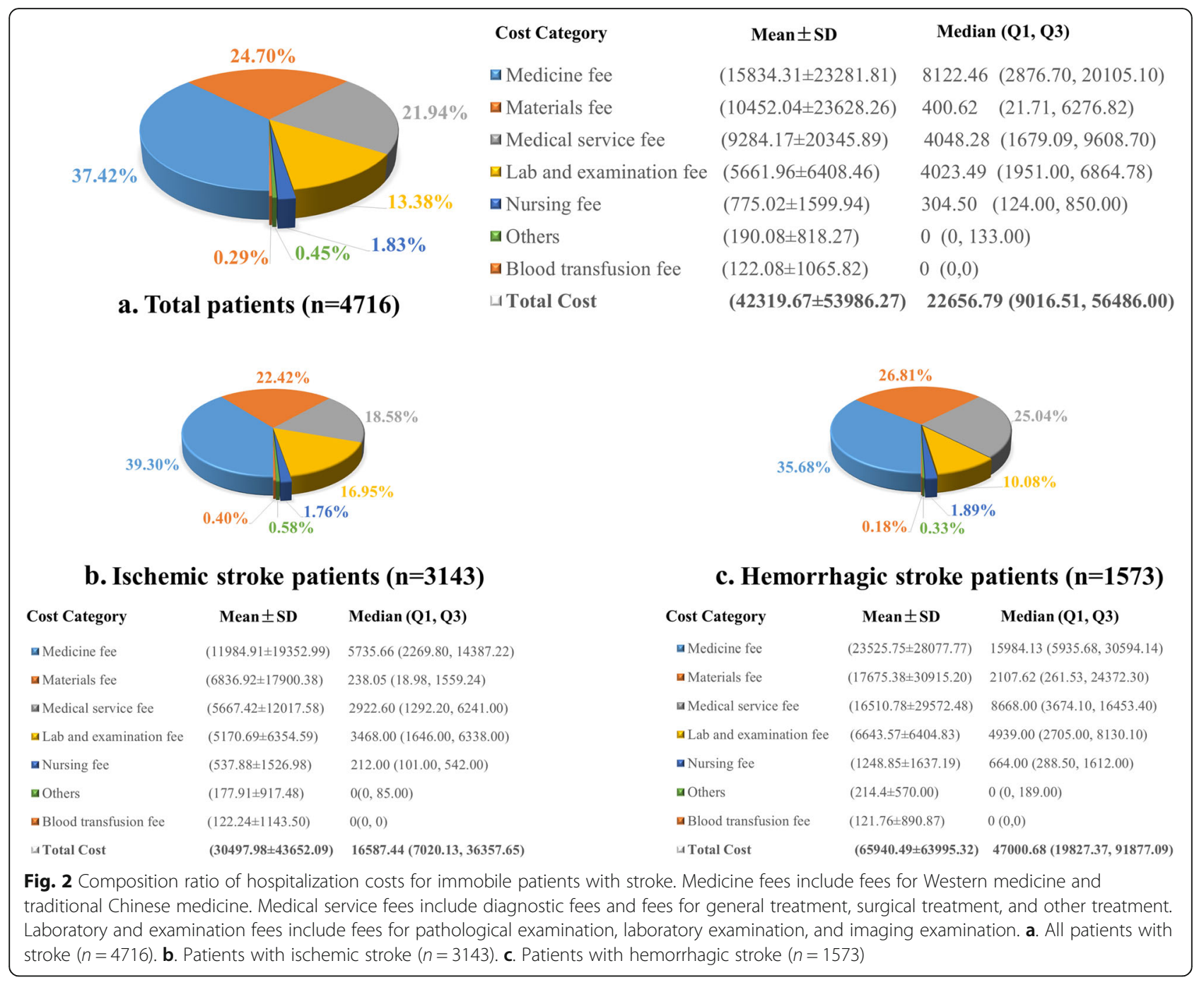

Table 2 Multivariate analysis for factors associated with hospitalization costs for immobile patients with stroke (adjusted $R^{2}=0.512$ )

\begin{tabular}{|c|c|c|c|c|c|}
\hline & \multicolumn{2}{|c|}{ regression coefficient } & \multirow{2}{*}{$\begin{array}{l}\text { standardization } \\
\text { coefficient }\end{array}$} & \multirow[t]{2}{*}{$t$} & \multirow[t]{2}{*}{$p$} \\
\hline & $\bar{B}$ & $\mathrm{SE}$ & & & \\
\hline constant & $-15,425.23$ & 1185.55 & & -13.01 & $<0.001$ \\
\hline LOS & 1435.76 & 48.53 & 0.316 & 29.585 & $<0.001$ \\
\hline Hospital level & $25,918.73$ & 1270.08 & 0.226 & 20.407 & $<0.001$ \\
\hline Previous surgery & $25,707.62$ & 1573.24 & 0.190 & 16.341 & $<0.001$ \\
\hline Previous ICU admission & $18,932.86$ & 1631.18 & 0.142 & 11.607 & $<0.001$ \\
\hline Urethral invasive operation & $11,917.18$ & 1342.77 & 0.106 & 8.875 & $<0.001$ \\
\hline Invasive ventilation therapy & $20,361.28$ & 2193.23 & 0.117 & 9.284 & $<0.001$ \\
\hline Respiratory invasive operation & $36,370.48$ & 4474.34 & 0.084 & 8.129 & $<0.001$ \\
\hline Pneumonia & $11,114.14$ & 1990.73 & 0.062 & 5.583 & $<0.001$ \\
\hline Stroke subtype (hemorrhagic stroke) & 5660.20 & 1286.94 & 0.049 & 4.398 & $<0.001$ \\
\hline
\end{tabular}

Abbreviation: LoS length of stay, ICU intensive care unit, SE standard error 
Table 3 Multivariate analysis for factors associated with hospitalization costs in immobile patients with hemorrhagic stroke (adjusted $\left.R^{2}=0.421\right)$

\begin{tabular}{|c|c|c|c|c|c|}
\hline & \multicolumn{2}{|c|}{ regression coefficient } & \multirow{2}{*}{$\begin{array}{l}\text { standardization } \\
\text { coefficient }\end{array}$} & \multirow[t]{2}{*}{$t$} & \multirow[t]{2}{*}{$p$} \\
\hline & $\bar{B}$ & SE & & & \\
\hline constant & $-32,229.38$ & 3939.29 & & -8.182 & $<0.001$ \\
\hline Hospital level & $45,490.24$ & 3630.41 & 0.260 & 12.53 & $<0.001$ \\
\hline LoS & 1183.95 & 147.76 & 0.228 & 8.013 & $<0.001$ \\
\hline Previous surgery & $30,524.34$ & 2798.87 & 0.228 & 10.906 & $<0.001$ \\
\hline Duration of immobility & 930.61 & 186.11 & 0.145 & 5 & $<0.001$ \\
\hline Previous ICU admission & $18,562.96$ & 3051.55 & 0.140 & 6.083 & $<0.001$ \\
\hline Respiratory invasive operation & $38,566.54$ & 7442.69 & 0.102 & 5.182 & $<0.001$ \\
\hline Urethral invasive operation & $12,211.79$ & 2568.11 & 0.101 & 4.755 & $<0.001$ \\
\hline Invasive ventilation therapy & $15,288.83$ & 3670.33 & 0.097 & 4.166 & 0.001 \\
\hline
\end{tabular}

Abbreviations: LoS length of stay, ICU intensive care unit, SE standard error

the Chinese population, based on a prospective multicenter study.

In the present study, the mean (median) hospitalization costs per person were RMB 442,319.67 $\pm 53,986.27$ (RMB 22,656.79; IQR 9016.51, 56,486.00), which are lower than those in developed countries of North America and Europe, as well as in Japan. A study in the United States indicated that the average cost of stroke was USD 20,396 \pm 23,256 (RMB 141,652.26 $\pm 161,515.25$, the spending estimates were converted to RMB (CNY) based on exchange rates in $2008(1 \mathrm{USD}=6.9451 \mathrm{CNY}))$ [17]. Research from Germany suggested that the mean hospitalization cost for hemorrhagic stroke was 26,602 USD (RMB 220,222.00, the spending estimates were converted to RMB (CNY) based on exchange rates in $2000(1 \mathrm{USD}=8.2784 \mathrm{CNY})$ ) [18]. Tu et al. studied hospitalized patients with ischemic stroke in Japan (from 1995 to 1999) and found that the mean (median) hospital charges per patient were USD 9020 (USD 7974) (RMB 74,681.99 (RMB 66,021.53), the spending estimates were converted to RMB (CNY) based on exchange rates in 1999 (1 USD = 8.2796 CNY)) [19].

Additionally, hospitalization costs were notably higher in IHS than IIS (RMB 47,000.68, IQR 19,827.37, 91, 877.09 vs. RMB $16,587.44$, IQR $7020.13,36,357.65)$. It is plausible that IHS tend to require more complex medical treatment or nursing interventions than IIS; thus, the median materials fees, medical service fees, and total costs for patients with severe illness may be higher in IHS. This is in line with the results of other resource-use studies indicating higher costs in patients with hemorrhagic stroke than in those who have ischemic stroke $[10,11]$. Therefore, it is necessary to increase the reimbursement ratio of medical insurance for patients with hemorrhagic stroke, to reduce the personal medical expenses of these patients.

As for cost composition analysis, we found that medicine fees represented the largest proportion of overall hospitalization costs (as high as 37.42\%); materials fees

Table 4 Multivariate analysis for factors associated with hospitalization costs for immobile patients with ischemic stroke (adjusted $\left.R^{2}=0.536\right)$

\begin{tabular}{|c|c|c|c|c|c|}
\hline & \multicolumn{2}{|c|}{ regression coefficient } & \multirow{2}{*}{$\begin{array}{l}\text { standardization } \\
\text { coefficient }\end{array}$} & \multirow[t]{2}{*}{$t$} & \multirow[t]{2}{*}{$p$} \\
\hline & $\bar{B}$ & SE & & & \\
\hline constant & $-11,583.29$ & 1029.58 & & -11.251 & $<0.001$ \\
\hline LoS & 1391.41 & 48.35 & 0.368 & 28.779 & $<0.001$ \\
\hline Hospital level & $20,851.95$ & 1145.30 & 0.236 & 18.207 & $<0.001$ \\
\hline Previous ICU admission & $20,012.31$ & 1815.94 & 0.152 & 11.020 & $<0.001$ \\
\hline Invasive ventilation therapy & $27,413.61$ & 2665.64 & 0.147 & 10.284 & $<0.001$ \\
\hline Previous surgery & $19,936.57$ & 1833.14 & 0.149 & 10.876 & $<0.001$ \\
\hline Urethral invasive operation & $10,338.59$ & 1454.75 & 0.099 & 7.107 & $<0.001$ \\
\hline DVT & $30,242.50$ & 5954.05 & 0.063 & 5.079 & $<0.001$ \\
\hline Respiratory invasive operation & $30,398.73$ & 5639.84 & 0.067 & 5.390 & $<0.001$ \\
\hline Pneumonia & $10,960.55$ & 2085.26 & 0.067 & 5.256 & $<0.001$ \\
\hline
\end{tabular}

Abbreviations: LoS length of stay, ICU intensive care unit, SE standard error, DVT deep vein thrombosis 
(24.70\%) and medical service fees (21.94\%) ranked second and third in the total hospitalization costs. Also, the composition of hospitalization costs is parallel in IHS or IIS. Compared with other studies carried out in China, the cost composition is mostly consistent with those in previous studies whereas the proportion of medicine fees is lower $[7,10,11]$. This may be attributable to the large reform to China's health system implemented in public hospitals during the past decade, which imposed zero markup on drug costs and encouraged the use of inexpensive medications [20,21].

In contrast, the cost composition in our study was quite different from those reported in Western countries. In Greece, Gioldasis et al. indicated that only about $7 \%$ of the total charges for stroke was attributable to medicines [22]. In Germany, Dodel et al. suggested that the costs for medicines were low, with a mean total cost of EUR $120 \pm 240$ [18]. Asil et al. analyzed the direct costs of acute ischemic and hemorrhagic stroke in Turkey, indicating that $29.9 \%$ of the total charge was for medicine [23]. For one thing, perhaps because most patients enrolled in this study ended up with complications thereby requiring more medications. For another thing, the Chinese government has made great efforts to reduce prescribing and medicine costs; however, the government must further standardize medical treatment and introduce additional and more effective policies. Dodel et al. suggested that nursing fees are related to the hospital LoS [18]. The average LoS in this study was $15.45 \pm 11.89$ days for all patients with stroke, which is longer than in developed countries, yet the nursing fees only accounted for a minimum proportion (1.83\%) of the total costs, which is lower than the $8 \%$ in Greece [22]. However, countries may differ in their developmental level and medical insurance service systems. Therefore, longitudinal comparisons within countries in this regard are more important than comparisons between countries.

In linear regression analysis, LoS, hospital level, previous surgery, previous ICU admission, invasive ventilation therapy, urethral invasive operation, respiratory invasive operation, pneumonia, and stroke subtype (hemorrhagic stroke) were found to be significantly associated with hospitalization costs for all immobile patients with stroke in this study. Identifying such factors can help to understand the nature of hospitalization expenses, so as to improve the efficiency of health care delivery. LoS was highly correlated with the hospitalization costs for immobile patients with stroke, which is in accordance with the results of several previous studies $[11,12,17$, $22,23]$. LoS is closely related to medical complications after stroke [24], the complication rates in this study were higher than those for previous studies; thus, as a controllable factor, LoS can be shortened by preventing nosocomial infections and medical complications. Other contributors such as hospital level, previous surgery, previous ICU admission, invasive ventilation therapy, urethral and respiratory invasive operations, and stroke subtype may represent the severity of illness.

The average LoS for all immobile patients with stroke was $15.45 \pm 11.89$ days in this study, which is longer than in previous reports from China $[10,11]$ and Europe [18, 22]. In most countries, patients with stroke are hospitalized for a short period of 10 to 15 days [5]. The potential reasons for the difference in our results may be that patients in this study were immobile and were therefore more susceptible to medical complications such as pneumonia, PI, and so on, which could prolong LoS [24, 25]. Moreover, patients with hemorrhagic stroke had longer LoS than those with ischemic stroke, which was consistent with earlier reports on ischemic and hemorrhagic stroke in China from 2015 to 2018 [10-12]. Previous studies have identified that payment type influences stroke costs $[6,10]$. In our study, 2023 patients $(42.9 \%)$ who were covered by the NCMS had lower costs, possibly because this type of payment forces hospitals to control costs with shorter LoS.

Subgroup analysis indicated that hospital level was highly correlated with the hospitalization costs for IHS. The potential reasons for this difference may be that hemorrhagic stroke is less prevalent but more likely to be fatal [26], and patients with more severe physical impairment definitely require more medical care resources $[12,15,27]$. Tertiary hospitals are top-level hospitals in China, in which the health services and medical resources are more advanced. Therefore, patients with severe neurological impairment tend to be treated in tertiary hospitals. Furthermore, the professional level of physicians in tertiary hospitals is generally higher, and more advanced professional skills are related to higher medical service fees [11, 12, 22].

Our study findings also suggested that pneumonia and DVT were significantly associated with hospitalization costs in IIS. However, the complication rates in our study were somewhat higher than those of previous studies (DVT: $0.8 \%$ vs. $0.2 \%$ [28]; pneumonia: $7.8 \%$ vs. $4.6 \%$ [29]). Balami et al. [30] and Bustamante et al. [31] indicated that complications after ischemic stroke could prolong the LoS, which may explain the impact of DVT and pneumonia on hospitalization costs for ischemic stroke $[24,32]$.

The duration of immobility was another significant predictor in the patient subgroup with hemorrhagic but not ischemic stroke. The duration of immobility after hemorrhagic stroke was longer than that after ischemic stroke $(12.11 \pm 9.98$ days vs. $7.36 \pm 9.77$ days $)$ in our sample. In addition, complications such as pneumonia or DVT can arise as a direct consequence of stroke itself, 
owing to ensuing immobility or disability [24]. These complications present barriers to optimal recovery and positive clinical outcomes or they can increase the costs of hospital care when complications are non-fatal.

This study has some limitations. The cost data reported in the present study reflect only direct health care spending and do not account for indirect societal costs associated with rehabilitation and intangible costs to patients with stroke; further research is required to estimate these costs and to obtain an estimate of the total costs for immobile patients with stroke. Given the cross-sectional nature of this study, we could not determine causation or the direction of the observed relationships. In addition, we were unable to assess all potentially associated factors that may determine hospitalization costs, such as alcohol use. For the univariate and multivariate analysis, when there is a large sample size, there is a tendency for small differences to become statistically significant. In Supplementary Tables 1 and 2, we can find actual cost difference is also very obvious in different categorical variables layers (such as subtype of stroke, age group, experience of surgery, experience of ICU, hospital level). This made us think that the test power of the analysis was in a relatively reasonable range. However, a more rigorous analytical method with more sophisticated evaluations are required to confirm our findings. The etiology, complications, and comorbidities for an ischemic stroke may potentially influence the initial cost of hospitalization. We will continue to explore in depth in the next step of the study.

The strength of our study is that we analyzed the distribution and predictors associated with hospitalization costs for different subtypes of stroke; patients enrolled in this study were from six regions of China, and this work was based on a prospective multicenter study. Therefore, our results will be valuable in economic evaluations to support policymaking regarding reimbursement, investment, and pricing for medical or nursing interventions. This study is of practical utility in developing countries and some developed countries aiming to provide comprehensive health services in immobile patients with stroke, to better balance patients' health gains, personal costs, and social welfare costs.

\section{Conclusion}

The findings of our study suggest that the cost composition for immobile patients with stroke in China is quite different from that in Western countries. The hospitalization costs are notably higher in IHS than in IIS. Medicine fees accounted for the largest proportion of hospitalization costs for these patients, far outweighing the proportions in developed countries of North America and Europe, perhaps because most patients ended up with complications such as pneumonia thereby requiring more medications. In addition, we found that LoS and hospital level were critical factors associated with hospitalization costs in immobile patients with both hemorrhagic and ischemic stroke. Reducing the economic burden of stroke in China can most likely be achieved by increasing the reimbursement ratio of medical insurance for IHS, decreasing medicine fees and LoS, preventing complications, and improving treatment capabilities.

\section{Supplementary information}

Supplementary information accompanies this paper at https://doi.org/10. 1186/s12913-020-05758-6.

\begin{abstract}
Additional file 1: Table S1. Univariate analysis for factors associated with hospitalization costs in all patients with stroke $(n=4716) .1)$ Wilcoxon signed-rank test; 2) Kruskal-Wallis test. Abbreviations: Q1, 1st quartile (25\%); Q3, 3rd quartile (75\%); CCl, Charlson Comorbidity Index; ICU, intensive care unit; $\mathrm{Pl}$, pressure injury; DVT, deep vein thrombosis; UTI, urinary tract infection; UEBMI, Urban Employee Basic Medical Insurance; URBMI, Urban Resident Basic Medical Insurance; NCMS, New Cooperative Medical System. Table S2. Univariate analysis for factors associated with hospitalization costs in patients with hemorrhagic stroke ( $n=1573)$. 1) Wilcoxon signed-rank test; 2) Kruskal-Wallis test. Abbreviations: Q1, 1st quartile (25\%); Q3, 3rd quartile (75\%); CCl, Charlson Comorbidity Index; ICU, intensive care unit; PI, pressure injury; DVT, deep vein thrombosis; UTI, urinary tract infection; UEBMI, Urban Employee Basic Medical Insurance; URBMI, Urban Resident Basic Medical Insurance; NCMS, New Cooperative Medical System. Table S3. Univariate analysis for factors associated with hospitalization costs in patients with ischemic stroke $(n=3143) .1)$ Wilcoxon signed-rank test; 2) Kruskal-Wallis test. Abbreviations: Q1, 1st quartile (25\%); Q3, 3rd quartile (75\%); CCl, Charlson Comorbidity Index; ICU, intensive care unit; PI, pressure injury; DVT, deep vein thrombosis; UTI, urinary tract infection; UEBMI, Urban Employee Basic Medical Insurance; URBMI, Urban Resident Basic Medical Insurance; NCMS, New Cooperative Medical System. Table S4. Multivariate analysis for factors associated with hospitalization costs for immobile patients with stroke. 1) Adjusted $R^{2}=0.512 ; 2$ ) adjusted $R^{2}=0.536 ; 3$ ) adjusted $R^{2}=$ 0.421 . ${ }^{*} P<0.001$. Abbreviations: LoS, length of stay; ICU, intensive care unit; SE, standard error; DVT, deep vein thrombosis.
\end{abstract}

\section{Abbreviations}

BMI: Body mass index; LoS: Length of stay; CCl: Charlson Comorbidity Index; ICU: Intensive care unit; PI: Pressure injury; DVT: Deep vein thrombosis; UTI: Urinary tract infection; UEBMI: Urban Employee Basic Medical Insurance (to support employed workers); URBMI: Urban Resident Basic Medical Insurance (to support urban residents without a stable job); NCMS: New cooperative medical system (to support rural residents); Q1: 1st quartile (25\%); Q3: 3rd quartile (75\%); SE: Standard error; SNIM: Standardized nursing intervention model

\section{Acknowledgments}

We would like to warmly thank the participants for their time and energy in volunteering for this study. We also thank Analisa Avila, ELS, of Liwen Bianji, Edanz Group China (www.liwenbianji.cn/ac), for editing the English text of a draft of this manuscript. We acknowledge the helpful comments by two anonymous reviewers.

\section{Authors' contributions}

Study concept and design: XWu and HL. Analysis and interpretation of data: CZ. Editing of the manuscript and drafting of tables: $\mathrm{HL}$ and CZ. Critical review of the manuscript for important intellectual content: $\mathrm{XWu}, \mathrm{JC}$, and JJia. Patient recruitment, data collection, and manuscript editing: CZ, BS, JJin, $\mathrm{YL}$, XWe, and SC. All authors critically reviewed and approved the manuscript before it was submitted. 


\section{Funding}

This work was supported by the National Health and Family Planning Commission (Beijing, China) [grant number 201502017]. The funding bodies had no specific role in study design or data collection, analysis, and interpretation, or manuscript conception and writing.

\section{Availability of data and materials}

The datasets generated for this study are available on request to the corresponding author.

\section{Ethics approval and consent to participate}

There are 25 cooperating hospitals in six provinces or municipality cities enrolled in this study. The tertiary hospital in each province are responsible for the ethical review of secondary hospitals and community hospitals in their province. Therefore, there are six IRBs approved our research. However, the Ethics Committee of Peking Union Medical College Hospital also contains the investigation content of the five other centers, the approval number is (S-700). The five other IRBs including: Henan Provincial People's Hospital (2014-022), the Second Affiliated Hospital Zhejiang University School of Medicine (2014-135), Wuhan Union Hospital (2014-303), Sichuan Provincial People's Hospital (2014-08), and the First Affiliated Hospital, Sun Yat-sen University (2014-10). Written informed consent was given by all patients enrolled in this study.

\section{Consent for publication}

Not applicable.

\section{Competing interests}

We declare no competing interests relevant to this manuscript.

\section{Author details}

${ }^{1}$ Department of Nursing, Chinese Academy of Medical Sciences - Peking Union Medical College, Peking Union Medical College Hospital, 1 Shuaifuyuan, Dongcheng District, Beijing 100730, China. ${ }^{2}$ Department of Nursing, Henan Provincial People's Hospital, No.7 Weiwu Road, Jinshui District, Zhengzhou 450003, China. ${ }^{3}$ The Second Affiliated Hospital Zhejiang University School of Medicine, No. 88 Jiefang Road, Hangzhou 310009, China. ${ }^{4}$ Department of Nursing, Wuhan Union Hospital, No.1277 Jiefangdadao, Jianghan District, Wuhan 430060, China. ${ }^{5}$ Department of Nursing, Sichuan Provincial People's Hospital, No. 32 West Second Section First Ring Road, Chengdu 610072, China. 'Department of Nursing, The First Affiliated Hospital, Sun Yat-sen University, No. 58 Zhongshan Second Road, Yuexiu District, Guangzhou 200032, China.

Received: 11 May 2020 Accepted: 22 September 2020

Published online: 29 September 2020

\section{References}

1. Feigin VL, Vos T, Nichols E, Owolabi MO, Carroll WM, Dichgans M, et al. The global burden of neurological disorders: translating evidence into policy. Lancet Neurol. 2020;19(3):255-65. https://doi.org/10.1016/S14744422(19)30411-9.

2. Hankey GJ. Stroke. Lancet. 2017;389(10069):641-54. https://doi.org/10.1016/ S0140-6736(16)30962-X.

3. Wang W, Jiang B, Sun H, Ru X, Sun D, Wang L, et al. Prevalence, Incidence and Mortality of Stroke in China: Results from a Nationwide PopulationBased Survey of 480,687 Adults. Circulation. 2017;135(8):759.

4. Wu S, Wu B, Liu M, Chen Z, Wang W, Anderson CS, et al. Stroke in China: advances and challenges in epidemiology, prevention, and management. Lancet Neurol. 2019;18(4):394-405.

5. Evers SM, Struijs JN, Ament AJ, van Genugten ML, Jager JH, van den Bos GA. International comparison of stroke cost studies. Stroke. 2004;35(5):120915. https://doi.org/10.1161/01.STR.0000125860.48180.48.

6. Liu L, Wang D, Wong KS, Wang Y. Stroke and stroke care in China: huge burden, significant workload, and a national priority. Stroke. 2011; 42(12):3651-4

7. Wu X, Zou S, Zhu B, Shi J. The hospital costs of stroke patients in Chinese island populations: an 11-year tendency analysis. J Stroke Cerebrovasc Dis. 2015;24(5):988-92. https://doi.org/10.1016/j.jstrokecerebrovasdis.2014.12.021.
8. Gruneir A, Griffith LE, Fisher K, Panjwani D, Gandhi S, Sheng L, et al. Increasing comorbidity and health services utilization in older adults with prior stroke. Neurology. 2016;87(20):2091-8.

9. Alberts MJ, Hademenos G, Latchaw RE, Jagoda A, Marler JR, Mayberg MR, et al. Recommendations for the establishment of primary stroke centers. Brain Attack Coalition. JAMA. 2000;283(23):3102-9.

10. Yin X, Huang L, Man X, Jiang Y, Zhao X, Zhao L, et al. Inpatient cost of stroke in Beijing: a descriptive analysis. Neuroepidemiology. 2018;51(3-4): 115-22.

11. Liu X, Kong D, Lian H, Zhao X, Zhao Y, Xu Q, et al. Distribution and predictors of hospital charges for haemorrhagic stroke patients in Beijing, China, March 2012 to February 2015: a retrospective study. BMJ Open. 2018; 8(3):e017693. https://doi.org/10.1136/bmjopen-2017-017693.

12. Kong D, Liu X, Lian H, Zhao X, Zhao $Y, X u$ Q, et al. Analysis of hospital charges of inpatients with acute ischemic stroke in Beijing, China, 2012 2015. Neuroepidemiology. 2018;50(1-2):63-73. https://doi.org/10.1159/ 000484212 .

13. Schwab ME. How hard is the CNS hardware? Nat Neurosci. 2010;13(12): 1444-6.

14. Kesarwani M, Perez A, Lopez VA, Wong ND, Franklin SS. Cardiovascular comorbidities and blood pressure control in stroke survivors. J Hypertens. 2009;27(5):1056-63.

15. Liu H, Zhu D, Cao J, Jiao J, Song B, Jin J, et al. The effects of a standardized nursing intervention model on immobile patients with stroke: a multicenter study in China. Eur J Cardiovasc Nurs. 2019;18(8):753-63. https://doi.org/10. $1177 / 1474515119872850$

16. Kokotailo RA, Hill MD. Coding of stroke and stroke risk factors using international classification of diseases, revisions 9 and 10. Stroke. 2005;36(8): 1776-81.

17. Wang G, Zhang Z, Ayala C, Dunet DO, Fang J, George MG. Costs of hospitalization for stroke patients aged 18-64 years in the United States. J Stroke Cerebrovasc Dis. 2014;23(5):861-8. https://doi.org/10.1016/j. jstrokecerebrovasdis.2013.07.017.

18. Dodel RC, Haacke C, Zamzow K, Paweilik S, Spottke A, Rethfeldt M, et al Resource utilization and costs of stroke unit care in Germany. Value Health. 2004;7(2):144-52.

19. Tu F, Anan M, Kiyohara Y, Okada Y, Nobutomo K. Analysis of hospital charges for ischemic stroke in Fukuoka, Japan. Health Policy. 2003;66(3): 239-46.

20. Shi X, Zhu D, Man X, Wang W, Zhu K, Nicholas S, et al. "The biggest reform to China's health system": did the zero-markup drug policy achieve its goal at traditional Chinese medicines county hospitals? Health Policy Plan. 2019. https://doi.org/10.1093/heapol/czz053.

21. Lu C, Zhang Z, Lan X. Impact of China's referral reform on the equity and spatial accessibility of healthcare resources: A case study of Beijing. Soc Sc Med. 2019;235:112386. https://doi.org/10.1016/j.socscimed.2019.112386.

22. Gioldasis G, Talelli P, Chroni E, Daouli J, Papapetropoulos T, Ellul J. Inhospital direct cost of acute ischemic and hemorrhagic stroke in Greece. Acta Neurol Scand. 2008;118(4):268-74. https://doi.org/10.1111/j.1600-0404. 2008.01014.x.

23. Asil T, Celik Y, Sut N, Celik AD, Balci K, Yilmaz A, et al. Cost of acute ischemic and hemorrhagic stroke in Turkey. Clin Neurol Neurosurg. 2011;113(2):111-4. https://doi.org/10.1016/j.clineuro.2010.09.014.

24. Kumar S, Selim MH, Caplan LR. Medical complications after stroke. Lancet Neurol. 2010;9(1):105-18.

25. Johnston KC, Li JY, Lyden PD, Hanson SK, Feasby TE, Adams RJ, et al. Medical and neurological complications of ischemic stroke: experience from the RANTTAS trial. RANTTAS investigators. Stroke. 1998;29(2):447-53.

26. $\mathrm{Lim} \mathrm{JH}$, Cheon SH. Analysis of variation in length of stay (LOS) after ischemic and hemorrhagic stroke using the Charlson comorbidity index (CCI). J Phys Ther Sci. 2015;27(3):799-803.

27. Mitchell JB, Ballard DJ, Whisnant JP, Ammering CJ, Samsa GP, Matchar DB. What role do neurologists play in determining the costs and outcomes of stroke patients? Stroke. 1996;27(11):1937-43. https://doi.org/10.1161/01.str. 27.11.1937.

28. Weimar C, Roth MP, Zillessen G, Glahn J, Wimmer ML, Busse O, et al. Complications following acute ischemic stroke. Eur Neurol. 2002;48(3):13340. https://doi.org/10.1159/000065512.

29. Shah SV, Corado C, Bergman D, Curran Y, Bernstein RA, Naidech AM, et al. Impact of Poststroke medical complications on 30-day readmission rate. J Stroke Cerebrovasc Dis. 2015;24(9):1969-77. 
30. Balami JS, Chen RL, Grunwald IQ, Buchan AM. Neurological complications of acute ischaemic stroke. Lancet Neurol. 2011;10(4):357-71. https://doi.org/10. 1016/S1474-4422(10)70313-6.

31. Bustamante A, García-Berrocoso T, Rodriquez N, Llombart V, Ribó M, Molina $C$, et al. Ischemic stroke outcome: a review of the influence of post-stroke complications within the different scenarios of stroke care. Eur J Intern Med 2016;29:9-21.

32. Chen $\mathrm{CM}$, Chang $\mathrm{CH}$, Hsu HC, Lin $\mathrm{CH}$, Chen KH. Factors predicting the total medical costs associated with first-ever ischeamic stroke patients transferred to the rehabilitation ward. J Rehabil Med. 2015;47(2):120-5. https://doi.org/ 10.2340/16501977-1894.

\section{Publisher's Note}

Springer Nature remains neutral with regard to jurisdictional claims in published maps and institutional affiliations.

Ready to submit your research? Choose BMC and benefit from:

- fast, convenient online submission

- thorough peer review by experienced researchers in your field

- rapid publication on acceptance

- support for research data, including large and complex data types

- gold Open Access which fosters wider collaboration and increased citations

- maximum visibility for your research: over $100 \mathrm{M}$ website views per year

At $\mathrm{BMC}$, research is always in progress.

Learn more biomedcentral.com/submissions 